this campus: When will other branch libraries be offering the service?

Since the program is similar to regular circulation we hope to make use of the circulation component of the integrated library system (LS/2000) currently being installed in the branch. This should reduce the load of manual record keeping for the service. A PC-based database of faculty names, campus addresses, and requested titles has already been created. Future development of the service could include evaluation by means of brief questionnaires and wider promotion. Eventually, when more full text articles are available online and subscriptions to printed journals decline, the old ballgame will become obsolete.

\title{
Innovations: Allocating one-time funds on the basis of weighted need
}

\author{
By Rickey D. Best \\ Archivist and Special Collections Librarian \\ Auburn University at Montgomery
}

In December 1989, the Auburn University at Montgomery Library received $\$ 200,000$ in onetime money from the University administration, to be used for the purchase of library materials. Because the acquisitions staff is small (one professional, two paraprofessionals and two students), the influx of these funds on top of the allocations already made for the fiscal year would have swamped the unit.

To prevent creating an unmanageable burden on the acquisitions staff and to ensure that the available monies were spent as effectively as possible, the library began examining ways to allocate the funds. Traditionally, funds were allocated to the teaching faculty of the university's five schools (Business, Education, Liberal Arts, Nursing, and Sciences) according to a formula which took into account the credit hour production of each of the schools and each of the departments within the school. Using credit hour production as the driving mechanism for dividing the funds, however, fails to take into account the needs of the various programs or differences in costs associated with meeting those needs. In considering how to spend the new monies, two elements were needed:

- a plan that would ensure the efficient and effective expenditure of resources by permitting the library to funnel monies into those areas of the collection showing the greatest need; and

- a formula to fairly match the allocations with collection needs.

After much discussion, it was determined that the most efficient method of expending the onetime funds was approval plans. These plans would permit the library to acquire current materials in support of the university curriculum while permitting the teaching faculty to use their allocations to purchase retrospectively. Three vendors were invited to make presentations: Blackwell North America, Baker and Taylor, and Yankee Book Peddler. Blackwell's approval plan was chosen for breadth of coverage, discounts, availability of electronic ordering, and the management reports offered.

With a vendor selected, the library was now required to determine the allocations for the approval plan. The library staff worked with Vaughn Judd, an assistant professor of marketing in the school of business, to devise a formula that would identify the relative needs of the collection.

Before the formula could be constructed, the collection needed to be measured against something. Books for College Libraries, 4th ed. was selected for comparison because of its breadth of coverage and because it emphasizes the holdings of undergraduate libraries.

The formula developed included the number of books BCL listed for a subject, the number of books included on the BCL list but missing from the library collection (based upon a sample), the percentage of deficiency (the number of books in the core list which the library lacked divided by the total number of books for the subject in the list), the average book cost, the deficiency cost (number of books deficient $\leftrightarrow$ average cost per book) and the weighted need (deficiency cost $\leftrightarrow$ percentage of deficiency).

To determine the number of books the library lacked, the staff began sampling the collection. Matching the number of titles held against the 
number of recommended titles in Books for College Libraries gave us a view of the relative strengths and weaknesses of the collection by providing a percentage of deficiency. For example, in history a total of 4,657 titles are recommended on the core list. Our sample suggested that the library lacked 3,260 of the recommended titles, or $70 \%$. The deficiency cost of this portion of the collection was the average cost per book in history $(\$ 25) \leftrightarrow$ the number of books deficient, or $\$ 81,500$. To determine the weighted need for history, the deficiency cost was multiplied by the percentage of the deficiency $(\$ 81,500 \leftrightarrow 70 \%)$, resulting in a weighted need of $\$ 57,050$. This is the estimated cost for adding to the collection the titles in the core list that the library lacks.

Weighted needs were determined for all of the five schools in the university, with each subject being identified as a percentage of the total weighted need of the school to which it belonged. The percentages derived from this process were applied to the available funds in order to derive an appropriate allocation.

The chart below shows the application of the formula for the departments in the school of liberal arts and the determination of that school's portion of the total allocation using the formula.

The use of this formula provided the library with an objective means of determining need based upon measuring the library's holdings against a list of recommended titles.

The total weighted needs were added up and divided into the total of the individual departmental weighted needs, providing a percentage of the total weighted need to be allocated to the department. The percentage was multiplied by $\$ 200,000$, the amount of the allocation, to determine the individual portion of the allocation for each department.
Using the one-time allocation to establish approval plans for the various departments has permitted the library to focus upon maintaining current levels of acquisition. The formula used in this instance permits the library to identify those areas of the collection having the greatest need and to focus funding to strengthen those areas.

Certain problems are inherent in the application of a formula such as the one described above. Problems include: 1) the failure of the formula to take into consideration the interdisciplinary nature of certain fields and 2) the failure to factor differences in behavior among the disciplines into the formula. Fields such as business and the hard sciences, which make a greater use of serials, benefit disproportionately in terms of monographic allocations. Because the formula was not considered for the allocation of serial monies, those fields requiring greater expenditures for serials received larger allocations for monographic materials. Perhaps the most significant drawback to the formula is the use of historical data to determine increases in the current acquisitions levels. Discrepancies between the collection and the core list, in this case Books for College Libraries, remain unless funds are devoted to the acquisition of retrospective materials. However, the use of the formula, based upon matching collection strengths against a core list, has great flexibility in that more detailed and appropriate lists can be developed for specific subjects. The formula also takes into consideration variations in average book costs for different subjects while identifying the expenditures necessary to rectify deficiencies in particular areas.

While not without some drawbacks, the use of the formula described above provides a reasonable method of allocating funds quickly, while taking into account the relative strengths and weaknesses of a collection.

APPLICATION OF THE ALLOCATION FORMULA

\begin{tabular}{|c|c|c|c|c|c|c|}
\hline Discipline & \# BCL & \# Lacked & \% Lacked & Avg. Cost & Deficiency Cost & Weighted Need \\
\hline History & 4,657 & 3,260 & $70 \%$ & $\$ 25$ & $\$ 81,500$ & $\$ 57,050$ \\
\hline English & 6,938 & 4,870 & $70 \%$ & $\$ 28$ & $\$ 136,360$ & $\$ 95,452$ \\
\hline Sociology & 1,234 & 852 & $56 \%$ & $\$ 29$ & $\$ 24,708$ & $\$ 16,060$ \\
\hline Anthropology & 179 & 41 & $77 \%$ & $\$ 31$ & $\$ 4,278$ & $\$ 3,294$ \\
\hline Geography & 196 & 61 & $69 \%$ & $\$ 43$ & $\$ 5,805$ & $\$ 4,005$ \\
\hline Fine Arts & 1,086 & 924 & $85 \%$ & $\$ 43$ & $\$ 39,732$ & $\$ 33,772$ \\
\hline Music & 575 & 379 & $83 \%$ & $\$ 43$ & $\$ 16,297$ & $\$ 13,526$ \\
\hline Theatre & 313 & 241 & $77 \%$ & $\$ 43$ & $\$ 10,363$ & $\$ 7,979$ \\
\hline \multirow[t]{6}{*}{ Communication } & 111 & 64 & $58 \%$ & $\$ 28$ & $\$ 1,792$ & $\$ 1,039$ \\
\hline & \multicolumn{2}{|c|}{ Discipline } & Allocation & \multicolumn{2}{|c|}{ Discipline } & Allocation \\
\hline & \multirow{2}{*}{\multicolumn{2}{|c|}{ History }} & & Fine Arts & \multicolumn{2}{|c|}{$\$ 13,545$} \\
\hline & & & $\$ 29,575$ & Music & \multicolumn{2}{|c|}{$\$ 6,618$} \\
\hline & \multicolumn{2}{|c|}{ English } & $\$ 45,223$ & Theatre & $\$ 3$ & \\
\hline & \multicolumn{2}{|c|}{ Sociology } & $\$ 9,927$ & \multicolumn{2}{|c|}{ Communication } & \\
\hline
\end{tabular}




\section{FES INDEX plus TEXT on COMPACT DISC}

\section{Developed for Public and Academic Libraries}

Indexes, abstracts and full text ...

- for all manufacturing and service industries

- from more than 1,000 key business and trade publications

- covering North America, Europe, Latin America and the Pacific Rim

available with SilverPlatter Information Retrieval Software

Plus, you own the annual archival disc, and there's no extra charge for LANs!

\section{For more information and a free brochure, call Predicasts today!}

